region of strontium oxide with interstitial barium, (e) a surface potential barrier, the height of which may be influenced by an adsorbed barium layer. To determine the relative importance of the various factors and to fill in the details will require extensive work, both theoretical and experimental. Dr. Vick concluded the opening paper by outlining part of the programme of work recently commenced at the University of Manchester. C. A. Walley is applying the mass-spectrograph technique to identify the positive and negative ions emitted from oxide cathodes during activation and at all stages of life, and to correlate the ion currents with cathode structure and thermionic properties. W. Grattidge is studying methods of forming oxide cathodes without starting with the carbonates or using an organic binder, the aim being to obtain coatings with relatively simple and reproducible physical structures.

The next paper was contributed by Mr. D. A. Wright, of the Research Laboratories, General Electric Co. Ltd., Wembley, who dealt first with the factors affecting total coating resistance. He has applied the Mott ${ }^{11}$ and Schottky ${ }^{12}$ theories of barrierlayer rectification to the core-oxide interface. A potential barrier is to be expected at the interface, the difference between the work functions of the metal and of the oxide semi-conductor giving its height. The flow of electrons from core to oxide is then determined by barrier height, temperature, potential gradient through the barrier and the electron mobility in it. Mr. Wright's experiments using a magnesium-nickel core and a single probe embedded in the oxide have confirmed the existence of the barrier layer, with an effective resistance at low currents of 2-4 ohms per sq. cm., rising to tens of ohms at saturation. Hence at high currents the P.D. across the barrier layer can rise to some hundreds of volts, possibly leading to dielectric breakdown. The barrier layer may limit the emission available from the cathode, and its capacitance introduces a time-constant affecting changes in emission. Fineman and Eisenstein ${ }^{10}$ have shown that the true coating resistance away from the barrier layer is of the order of $1 \mathrm{ohm}$ per sq. $\mathrm{cm}$. To lower the true coating resistance in the presence of a high-resistance barrier layer would give little overall gain in performance, but if the barrier layer resistance could be lowered at the same time, a considerable gain would be possible.

With a magnesium-nickel core, the height of the potential barrier at the core interface has been estimated to be about $0.7 \mathrm{eV}$. Mr. Wright's recent calculations show that the bottom of the conduction bands in $\mathrm{BaO}, \mathrm{SrO}$ and $\mathrm{CaO}$ is not more than about $\mathbf{0 . 5} \mathrm{eV}$. below the zero-level. Conductivity measurements show that the impurity-levels of interstitial barium in barium oxide are between 1.0 and $1.5 \mathrm{eV}$. below the bottom of the conduction band. This gives a work function of $1 \cdot 0-1 \cdot 3 \mathrm{eV}$. Since this is of the same order as the observed work function for an oxide cathode, it indicates that any adsorbed barium on the surface has a small influence only on the work function. This is in agreement with the results of Nishibori and Kawamura ${ }^{13}$. In order to reconcile the value of the work function of the oxide with $4 \cdot 6 \mathrm{eV}$. for nickel and the barrier height of $0.7 \mathrm{eV}$., it seems necessary to assume the presence of barium at the core-oxide interface.

Treating the observed emission as from an excess semi-conductor, assuming that the concentration of interstitial barium is $5 \times 10^{17}$ atoms per c.c., the resistivity at $700^{\circ} \mathrm{C}$. is calculated to be $300 \mathrm{ohm}$. cm., and the saturated emission 50 amp. per sq. cm., agreeing reasonably well with experiment. Methods of reducing effective resistance are being explored in the G.E.C. Research Laboratories.

Mr. Wright concluded his paper by suggesting a reason for the most effective cathodes being those with approximately equimolecular proportions of barium and strontium oxides. The reasoning is based on a minimum work function for interstitial barium in the surface layers of strontium oxide.

These two opening papers provoked a lively discussion which raised many points of detail for which there is no space in this brief summary. Mr. T. J. Jones (Admiralty Signals Establishment) directed attention to additional arguments in favour of an adsorbed barium layer being a predominant factor in controlling the effective thermionic emission. In one of his experiments ${ }^{14}$ the outer layers only of an activated cathode were removed in a vacuum; this caused the emission to fall to about one thousandth. Subsequent operation at a suitable temperature restored the activity. Mr. Wright said that his own work and that of others had now stressed the importance of the core-oxide interface.

The last paper was contributed by Mr. A. J. H. Darlaston, of the Cosmos Manufacturing Co. Ltd., who gave a brief account of the preparation of oxide cathodes.

A fuller account of the proceedings at the meeting will be published in The Journal of Scientific Instruments. F. A. VIOK

1 Koller, L. R., Phys. Rev., 25, 671 (1925).

' Becker, J. A., Phys. Rev., 34, 1323 (1929).

${ }^{3}$ Becker, J. A., and Sears, R. W., Phys. Rev., 38, 2193 (1931).

- Reimann, A. L., "Thermionic Emission" (1934), 212.

${ }^{5}$ Lowry, E. F., Phys. Rev., 35, 1367 (1930).

- Relmann, A. L., and Murgoci, R., Phil. Mag., 9, 440 (1930).

' Sproull, R. L., Phys. Rev., 67, 166 (1945).

' Coomes, E. A., J. Appl. Phys., 17, 647 (1946).

- Eisenstein, A., J. Appl. Phys., 17, 434 and 654 (1946).

${ }^{10}$ Fineman, A., and Eisenstein, A., $J$. Appl. Phys., 17, 663 (1946)

11 Mott, N. F., Proc. Roy. Soc., A, 171, 27 (1939).

12 Schottky, W., Z. Phys., 113, 367 (1939) and 118, 539 (1942); Phys Z., 41, 539 (1940).

18 Nishibori and Kawamura, Phys. Math. Soc. Japan, 22, 378 (1940). "Jones, T. J., "Thermionic Emission", 82' (1936).

Gentrat :

Blewett, J. P., J. Appl. Phys., 10, 668 and 881 (1939); 17, 643 (1946)

Vick, F. A., Sci. Prog., 35, 82 (1947)

Weinreich, O., Rev. Gen. Elect., 46, 75 (1947).

Hermann, G., and Wagener, S., "Die Oxydkathode" (1944).

\section{TYPHUS RESEARCH}

$\mathrm{T}$ recent years research upon typhus has provided one of the best examples of the beneficent effects of international co-operation in scientific work. By agreement with workers in the United States and Canada, publication of many aspects of the work done on typhus at the National Institute for Medical Research, London, and at the Royal Army Medical College Emergency Vaccine Laboratory, Everleigh, Wilts, has been withheld. A full account of important parts of this work has now been issued*.

The researches of twelve workers are here recorded and Dr. C. H. Andrewes contributes a general introduc.

* Medical Research Council. Special Report Series, No. 255 : Chemotherapeutic and Other Studies of Typhus. By M. van den Ende, C. H. Stuart-Harris, F. FuIton and J. S. F. Niven, with C. H. Andrewes A. M. Begg, W. J. Elford, M. H. Gleeson White, W. I. Andrewes, A. C. Mills, F. Hamilton and C. C. Thomas. Pp. ii $+246+$ 11 plates. (London: H.M. Stationery Office, 1946.) 128. 6d. net. 


\section{No. 4073 November 22, $1947 \quad$ N A T U R E}

tion in which he explains that the report is not a comprehensive treatise on the clinical and pathological aspects of typhus, although it contains useful descriptions of these aspects of the disease, and specially of the Naples epidemic, which occurred between January and March, 1944, and is likely to have considerable historic interest. The report consists of five sections. Section 1 deals with the toxicity of two sulphonamides ( $V 147$ and $V 186$ ), the highly promising activity of which against the murine type of typhus in mice had been studied earlier by Andrewes and his collaborators. Section 2 discusses in great detail the chemotherapeutic trials of these drugs in North Africa and at Naples, and the pathological studies associated with this part of the work. The two sulphonamides failed to fulfil the expectation raised by the earlier results obtained in mice, and the possible reasons for this failure are discussed. Section 3 describes a quantitative test for neutralizing antibodies against typhus Rickettsiæ. Section 4 discusses the comparison of four murine typhus vaccines in the laboratory and gives methods for the preparation of these vaccines. Section 5 compares the antigenic structure of a murine strain of typhus Rickettsiæ with that of a strain of epidemic typhus Rickettsiæ. The report concludes with two appendixes, one giving illustrative case reports and the other a list of drugs tested for chemotherapeutic activity against experimental typhus infection in mice.

It is impossible, of course, in a brief space to do more than indicate, as the preceding paragraph attempts to do, the solid value of every page of this report. It is an indispensable addition to the library of every worker on typhus and contains much that will interest the historian. Reading between the lines, one gets glimpses of Naples early in 1944, when the Italian civil authorities helped by their complete co-operation, although one of the immense difficulties encountered was the concealment of illness by the Italian community. The photograph published of an Italian deep underground air raid shelter, coupled with a little imagination and a dash of memory of Italy in happier days, makes it easy to visualize how a typhus epidemic can play havoc under the conditions then prevailing. The story of the dramatic effects of D.D.T. upon the lice vectors of the disease has been told elsewhere. Dr. C. H. Andrewes mentions that, when the method of intranasal inoculation of mice with material containing typhus Rickettsiæ was first used, all five of the workers using this method at Hampstead became infected, "fortunately with murine, not epidemic, typhus", and nine others working at Everleigh were also infected; but after the invention by van den Ende of a special inoculation box only one other worker was infected at Hampstead during the ensuing two and a half years, while none was infected at Everleigh. This gives an idea of the risks taken by these workers. Although there is still no specific drug which has a specific action on typhus Rickettsiæ, nobody will doubt that one will eventually be found. When it is found, it seems likely that the study of its use will provide valuable information about possible chemotherapeutic methods of attack upon other organisms which have so far resisted all drugs used against them. As this report says (p. 126), modern chemotherapy of bacterial diseases is supposed to depend largely upon interference with essential metabolic processes of the organisms, but a similar basis for attacks on the virus and Rickettsial diseases may be impossible, because these organisms depend upon "parasitism of the enzymes and essential metabolites of the host's cells". Perhaps future work, using this idea as a clue, will succeed in mastering these causes of this devastating disease.

G. LAPAGE

\section{JAMES HUTTON: GEOLOGIST AND AGRICULTURIST}

$T$ HE first ordinary meeting this session of the Royal Society of Edinburgh was held on November 3 and took the form of a commemoration of the hundred and fiftieth anniversary of the death of James Hutton [see also p. 694].

Sir Edward Bailey, who spoke on "James Hutton : Founder of Modern Geology : 1726-1797', devoted much of his address to Hutton's unpublished "Principles of Agriculture". He said that to anyone perusing Hutton's immortal "Theory of the Earth", it is clear he pictured his subject as a well-managed agricultural estate with a rotation of processes designed to maintain continuing fertility. One might therefore have expected to find in his agricultural treatise merely a disguised reproduction of his well-known geological tenets. Such is far from the case. Hutton, who spoke to geologists of æons, spoke to farmers of seasons and years. His object was "to make philosophers of husbandmen and husbandmen of philosophers".

The work, if published in its day, would rank among the classics. Its interest is comprehensive. For example, one sentence from a discussion of possible diversification of species by natural selection is remarkable: "Where dogs are to live by the swiftness of their feet and the sharpness of their sight, the form best adapted to that end will be the most certain of remaining, while those forms which are least adapted to this manner of chase will be the first to perish". It must be remembered that this was written by a man who died eleven years before Charles Darwin was born. Similarly, Hutton's account of selection of a pure line of rice, somewhere about the year 1710, by the Emperor Kang-hi, makes it difficult to realize that, when its author died, Patrick Shirreff, famous as pioneer-isolator of profitable strains of wheat and oats, was only six years old.

Hutton's writings on climate and chemistry, physics and metaphysics, are less valuable than his contributions to geology and agriculture; but through them all can be seen the working of a single great idea, a balance of the powers of Nature, which leads to never-ending cyclic continuity. If in one direction Hutton noted destruction, he always found in another direction proof of reconstruction. Thus, in geology, his unaided eyes told him how agents of erosion, under the influence of gravity, were slowly washing the continents down into the sea; while his reason assured him with equal certainty from available evidence that there was internal heat in the earth, which would presently re-elevate the consolidated debris high above the reach of the waves. Among Hutton's other famous contributions to geology may be mentioned the following: granite is an igneous rock, a claim based upon a number of veined contacts; geological processes of the past have been of the same kind and intensity as those of the present ; the valley systems of the earth's surface have been sculptured by subaerial erosion operating through millions of years. 